The area is high technology but not wide spread, because the market is still very limited. Many European industries are investing $R$ \& $D$ effort in systems for biomagnetism, but to date only one small-sized American manufacturer is selling systems.

The workshop, help in the brand new, excellent facilities of the CNR Headquarters in Rome, brought together about 40 people from industry and the academic world. All the main industries operating in the field had been invited with the result that BTI (USA), Philips (FRG), CITEC (Italy) and ITHACI (Japan) took an active part sending particularly qualified representatives. Thanks to the single subject and the small number of ly atmosphere which stimulated a lot of interesting talk. The discussions were continued outside the scheduled hours including the long, and particularly enjoyed, Italian style lunch.

P. Carelli and

A. Paoletti participants, the workshop had a friend-

\section{Latest SUN Revision}

The SUN-AMCO Commission of the International Union of Pure and Applied Physics has published the third revision of its guide to authors and editors Symbols, Units, Nomenclature and Physical Constants. In addition to up-dating, sections have been regrouped and enlarged and more specific rulings have been given on such aspects as labelling tables and graphs. The new edition is easier to follow than its predecessor, helped also by the increased type size. Our warmest thanks to the editors, E.R. Cohen and P. Giacomo.

The booklet in its familiar red cover and referred to as Document I.U.P.A.P.25 (SUN-AMCO 87-1) may be obtained from the present Secretary of the SUNAMCO Commission:

Dr. B.W. Petley

National Physical Laboratory

Teddington, Middlesex TW11 OLW, UK

The price is $£ 2.00$ including postage, but $£ 2.00$ should be added for bank charges on cheques drawn on non-British banks.

\section{History of Physics}

Consequent on a decision of Council in Dresden, the Advisory Committee on Physics Education has now incorporated a Group concerned with the use of historical approaches in the teaching of physics. The Group's first activity under the auspices of EPS will be to hold a Europhysics Study Conference in Orsay (France) from 21-28 November 1988 on the following topics:

History of concept, Reconstruction of historical experiments,

Technology and society, Physics and culture,

Physics and other science.

The day of 14 November will be devoted to contacts between the participants and secondary school teachers of physics and related sciences.
The aim of the conference is to see to what extent it might be possible to produce some common basic teaching material covering these fields which could be translated or adapted to various European languages.

Since the participation is limited to 50 , those interested should write to:

Christine Blondel

Cité des Sciences et de I'Industrie F-75930 PARIS Cédex 19

stating explicitly what their contribution might be.

For further details on the Group, contact the Secretariat in Geneva or the Chairman of the Adv. Com. on Physics Education:

Institut de Physique

B-4000 SART-TILMAN (LIEGE 1)

or at DEPIREUX @ BLIULG11.BITNET.
Joseph DEPIREUX

\section{Meetings}

\section{Late announcement:}

14-20 October 1988

Turin, Italy

2nd International Topical Meeting on Optics of Liquid Crystals: Optics and Interfacial Phenomena in LC and Polymers.

Scientific Information:

P. Taverna and L. Trossi

Physics Department, Politecnico

1-10129 Torino (Italy)

PP / 100 / ISI / 250000 LIT

\section{Postponement:}

The Conference: Physics for Industry - Industry of Physics: Solid State Physics scheduled for Krakow, Poland in September 1989 has been postponed. The new date will be announced when available.

\section{Commercial Exhibit}

The Plasma Physics Division informs us that at the 16th European Conference on Controlled Fusion and Plasma Physics to be held in Venice from 13-17 March 1989, an exhibit for commercial firms supplying materials and equipment to the field will be organized.

Commercial firms interested in displaying small sized hardware or documentation on their products are kindly invited to ask for further information from:

Mrs. M. Polidoro

ENEA

Centro Ricerche Energia Frascati

C.P. 65

I-00044 FRASCATI (Roma)

Telephone: (6) 94005309

Telecopier: (6) 94005400

Telex: $\quad 610421$ ENEA FR I

\section{Europhysics News \\ Welcomes}

\section{Readers' Letters}

Europhysics News is the official journal of the European Physical Society which comprises 29 National Societies, Academies and Group, about 4000 Individual Members and 75 Associate Members. Governing bodies of EPS are the General Meeting, Council and an elected Executive Committee responsible for detailed policy. EPS promotes the collaboration of physicists throughout Europe, organising and harmonising conferences and publications, improving physics education, encouraging physics applications, awarding scholarships to sponsored schools in Erice. EPS publishes in addition to Europhys. News, Europhysics Letters lin addition to Europhys. News, Europhysics Letters (in of Physics (in partnership with The UK Inst. of Phys.), and European Conference Abstracts. Individual Mem. bers receive Europhys. News free of charge (price to insts.: Sw.Fr. 90.-1a), Europhys. Lett. at Sw.Fr. 125. -/a insts. SW.Fr. 90. - /a), Europhys. Lett. at Sw.Fr. 125.-/a
(insts. 1050.-1, rebates on many other publications and (insts. 1050--1, rebates on many other publications and dividual Members belonging to an EPS member society is: Sw.Fr. 44-; independent members: Sw.Fr. 132.-; members of a Collaborating Society: Sw.Fr. 55..

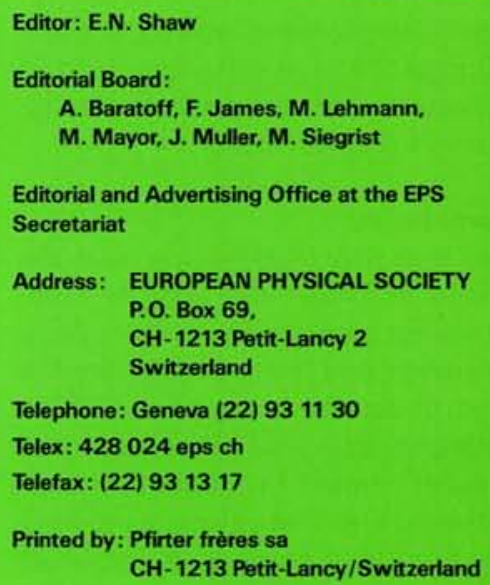

